\title{
Correlação de dados sísmicos multiescala e integração com arcabouço tectônico regional: exemplo da área do Domo de Piratininga, SP
}

\author{
Adriane Fátima de Campos ${ }^{1}$, Sidnei Pires Rostirolla ${ }^{2}$, Marcelo Kulevicz Bartoszeck, Marco \\ Antonio Thoaldo Romeiro ${ }^{3}$, Francisco José Fonseca Ferreira ${ }^{2}$ \& Chang Hung Kiang ${ }^{4}$
}

\begin{abstract}
Resumo A área de estudo abrange o domínio do Domo de Piratininga, representado por um alto estrutural, com seu ápice definido por um horst limitado por falhas. O objetivo geral deste estudo é estabelecer uma sistemática de imageamento sísmico de alta resolução e comparar com dados sísmicos convencionais, modelos digitais de elevação e dados de métodos potenciais, utilizando uma abordagem multiescala. Informações de subsuperfície compreendem uma linha sísmica com resolução convencional, com cerca de $80 \mathrm{~km}$ de comprimento, e perfil composto do poço 1-PA-1-SP. A interpretação da linha convencional foi desenvolvida no programa computacional Kingdom (Seismic Micro-Technology), visando identificar os principais horizontes sísmicos e sistemas de falhas. Para testar a hipótese de registro hierárquico multiescala de feições geológicas, foi adquirida uma linha sísmica de alta resolução, paralela e à pequena distância da linha convencional, com cerca de $1 \mathrm{~km}$ de comprimento e profundidade de investigação de aproximadamente 360 metros. O processamento foi realizado seguindo um fluxo padrão da técnica de empilhamento CDP, utilizando o programa computacional Vista (Gedco). Também foram utilizados dados altimétricos orbitais da Shuttle Radar Topography Mission (SRTM) e dados aeromagnetométricos dos Projetos Bauru e Botucatu, para interpretação de lineamentos. As correlações entre horizontes interpretados na linha regional e na linha de detalhe possibilitaram testar diferentes hipóteses para as feições estruturais e estratigráficas imageadas. Da mesma forma, a ampliação do conhecimento em escala de reservatório foi obtida a partir da extração de elementos geológicos hierárquicos em diferentes resoluções. Os resultados permitiram estabelecer a relação entre feições do arcabouço tectônico regional com estruturas interpretadas nos dados sísmicos. Estes resultados demonstram o potencial de aplicação da metodologia multiescala, como forma de facilitar e orientar o estudo de análogos de reservatórios.
\end{abstract}

Palavras-chave: sísmica, correlação mutiescala, integração geológica-geofísica.

\begin{abstract}
Multiscale seismic data correlation and integration with regional tectonic framework: example of the Piratininga Dome, SP. The study area covers the Piratininga Dome, a structural high composed by a center horst bordered by faults. The main objective of this work was to establish a systematic multiscale approach, in which high resolution seismic data was compared to conventional seismic, digital terrain models and geophysical potential data. The subsurface data include an $80 \mathrm{~km}$ conventional seismic section and the well 1-PA-1-SP. The Kingdon (Seismic Micro-Technology) software was used to interpret the seismic data in order to map the main horizons and faults. To test the multiscale hipothesys was acquired a high resolution seismic line just over the regional seismic trace. This detailed line measures $1 \mathrm{~km}$ length and 360m depth. The seismic processing was based on a conventional flowchart for CDP technique with Vista (Gedco) software. Shuttle Radar Topography Mission (SRTM) and aeromagnetic data of Botucatu and Bauru projects were used to the lineaments interpretation. Comparison between observed horizons in the high resolution and conventional seismic lines made possible to test different alternatives to map structural and stratigraphic features. The obtained multiscale geological elements hierarchies enlarge the knowledge in reservoir resolution. The results of the interpretation indicate the close relationship between regional structural framework and features observed in seismic data, and can be applied to enhance and guide the studies of analogous to depth reservoirs.
\end{abstract}

Keywords: seismic, multiscale correlation, geological-geophysical integration.

INTRODUÇÃO Na prospecção de hidrocarbonetos a sísmica de reflexão convencional é amplamente empregada, mas seu desafio principal tem sido alcançar grandes profundidades, com perda significativa de informação sob o ponto de vista de resolução. Em outras palavras, a sísmica convencional não permite a obser-

1 - Programa de Pós-Graduação em Geologia, Laboratório de Análise de Bacias e Petrofísica, UFPR, Curitiba (PR), Brasil. E-mail: adrianefcampos@yahoo.com.br

2 - Departamento de Geologia, UFPR, Curitiba (PR), Brasil e Pesquisadores do CNPq

3 - Programa de Iniciação Científica, Departamento de Geologia, UFPR, Curitiba (PR), Brasil

4 - Departamento de Geologia Aplicada, UNESP, Campus de Rio Claro, Rio Claro (SP), Brasil e Pesquisadores do CNPq 
vação da geometria em escala de reservatório.

No presente estudo a sísmica de alta resolução foi utilizada para complementar o imageamento de situações geológicas subaflorantes, em condições geológicas similares aos reservatórios que ocorrem a grandes profundidades. Constitui-se então em ferramenta auxiliar na determinação da geometria da situação rasa análoga, para fornecer subsídios à exploração de alvos profundos.

Diferentes métodos para interpretação e correlação de estruturas vem sendo executados na Bacia do Paraná ao longo do tempo. Entre os mais consagrados pode-se citar o mapeamento de superfície, métodos geofísicos magnetométricos e gravimétricos, além de análises morfoestruturais em imagens de radar e de satélite (Soares 1982, 1991, Ferreira 1982, Artur 1998, Zálan et al. 1987, De Freitas 2005).

Na década de 70 e 80 a Bacia do Paraná foi alvo de uma extensiva campanha de aquisição de dados sísmicos de reflexão. Foram realizados inúmeros projetos de levantamento de dados em escala regional, tanto pela Petrobras quanto por outras companhias (British Petroleum apud De Freitas 2005).

Com a criação do consórcio CESPE-IPT (PAULIPETRO 1981) ampliou-se o conhecimento da bacia, principalmente com relação ao empilhamento estratigráfico (cerca de 80 poços profundos foram perfurados) e à distribuição das unidades geológicas, através de mapeamentos geológicos e aerogeofísicos. A atividade do Núcleo de Exploração da Petrobras (NEXPAR), entre os anos 80 e 90, consolidou o quadro exploratório da bacia, resultando na descoberta de acumulações de gás e estabelecimento de um novo modelo para prospecção de hidrocarbonetos. Mais recentemente a Agência Nacional do Petróleo (ANP), através da Nona Rodada de Licitações, disponibilizou a investigação em diversas bacias terrestres, tanto em novas fronteiras exploratórias, ou seja, em regiões ainda pouco conhecidas geologicamente, quanto em bacias maduras, para dar continuidade à exploração e produção de petróleo e gás natural. A Universidade Federal do Paraná (UFPR), através de projetos de intercâmbio técnico-científico do Laboratório de Análise de Bacias e Petrofísica (LABAP), participa em co-parceria com o Petrobras em pesquisas na bacia, objetivando a modelagem de possíveis reservatórios análogos, usando trabalhos de campo e sísmica de alta resolução.

A área de estudo deste trabalho localiza-se no município de Agudos, aproximadamente $20 \mathrm{~km}$ a sudeste da cidade de Bauru. O acesso a partir da capital São Paulo é realizado através da Rodovia Presidente Castelo Branco (SP 280) até Itatinga, pela SP-209 até Botucatu e pela Rodovia Marechal Rondon (SP-300) até a cidade de Agudos, percorrendo cerca de $300 \mathrm{~km}$ da capital do estado até o local de interesse.

CONTEXTO GEOLÓGICO A área abrange o Domo de Piratininga, um alto estrutural representado por um horst limitado por falhas N40-60E, com exposição das formações Pirambóia e Teresina, em área de domínio das unidades cretáceas da Bacia do Paraná, Grupo Bauru.
O Grupo Bauru é uma seqüência sedimentar composta predominantemente por arenitos continentais, que recobre os derrames basálticos eocretáceos da Formação Serra Geral, com depocentro coincidente com a maior espessura da pilha de rochas vulcânicas (Riccomini 1997). A divisão estratigráfica clássica do Grupo Bauru no estado de São Paulo, proposta por Soares et al. (1980) e complementada por Suguio (1981) e Fernandes \& Coimbra (2000), compreende as formações Caiuá, Santo Anastácio, Adamantina, Marília, Araçatuba e Presidente Prudente. Na figura 1 estão representadas as relações estratigráficas entre as unidades ao longo de uma seção WNW-ESSE na porção sudeste no estado de São Paulo.

Segundo trabalhos anteriores (IPT 1981, Fernandes 1998) na área investigada afloram rochas das formações Teresina, Pirambóia, Vale do Rio do Peixe e Marília, além de intrusivas básicas mesozóicas e sedimentos cenozóicos indiferenciados (Fig. 2).

A área de ocorrência da Formação Teresina é restrita à porção central do Domo de Piratininga. Compreende estratos tabulares essencialmente pelíticos e carbonáticos, constituídos por siltitos e ritmitos lamítico-arenosos com horizontes de calcário, por vezes silicificado. Esta unidade acha-se intensamente afetada pela tectônica associada ao domo, estando as camadas basculadas para diferentes direções e com mergulhos na ordem de $20^{\circ}$ a $80^{\circ}$. A Formação Pirambóia também aflora na porção central da área, sendo as atitudes do acamamento concordantes com as da Formação Teresina e resultantes do mesmo contexto de deformação. No topo, seu contato é discordante com os estratos horizontalizados do Grupo Bauru, evidenciando forte angularidade. Esta unidade é composta por arenitos finos a médios, quartzosos e moderadamente selecionados. Predominam fácies com laminação horizontal e ondulações de corrente de pequeno porte. Diques de diabásio ocorrem intrudidos nos estratos da Formação Teresina. No geral, configuram cristas retilíneas bem marcadas na topografia, com direção NNE-SSW, e são associados à Formação Serra Geral. A Formação Botucatu apresenta constituição relativamente homogênea de arenitos quartzosos avermelhados, finos a médios, friáveis, com seleção boa a regular e pouca matriz. Os grãos são foscos e geralmente arredondados e normalmente apresentam bimodalidade. Ocorrem intercalações de arenitos argilosos, mal selecionados e, localmente, na porção basal da unidade, uma camada de arenito grosso a conglomerático pode estar presente. As estruturas sedimentares mais típicas são as estratificações cruzadas tangenciais em grandes cunhas, que para o topo, passam a estratificação plano-paralela e cruzada acanalada. Zonas silicificadas também são comuns nesses arenitos, principalmente na porção superior próximo ao contato com as vulcânicas da Formação Serra Geral. A Formação Adamantina constitui-se por uma associação de arenitos finos a muito finos e lamitos siltosos, com intercalações de argilitos. Dispõe-se normalmente em estratos maciços ou de acamamento plano-paralelo, alternados com camadas com estratificação cruzada de médio a 
WNW

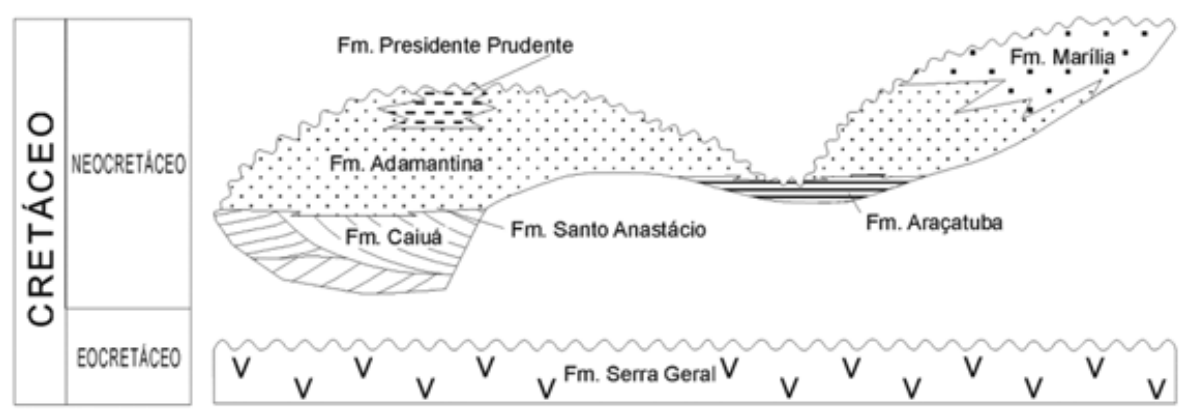

Figura 1 - Relações estratigráficas entre as unidades do Grupo Bauru no estado de São Paulo (modificado de Fernandes \& Coimbra 2000).

pequeno porte. A Formação Marília ocorre nas regiões topograficamente mais elevadas da área, configurando relevos escarpados. A parte basal desta formação corresponde a conglomerados e arenitos conglomeráticos, com pacotes de até 7 metros e espessura. Na parte intermediária ocorrem arenitos, dispostos em corpos tabulares de espessura métrica. Na parte superior ocorrem arenitos médios a grossos com cimentação carbonática, dispostos em corpos tabulares de 1 a 4 metros de espessura. Coberturas de sedimentos cenozóicos ocorrem distribuídas de forma descontínua em alguns locais da área. Na porção leste do domo constituem depósitos de areia e cascalho mal selecionados com estratificação cruzada planar de grande porte, principalmente associada a fácies de avalanche. Tais sedimentos representam provavelmente depósitos de tálus e/ou leques aluviais.

SÍSMICA DE REFLEXÃO Durante muito tempo à sísmica de reflexão tem sido aplicada com sucesso para investigar feições em subsuperfície para a exploração de hidrocarbonetos. Nos últimos 15 anos este método tem sido aplicado para resolver problemas de engenharia e ambientais como resultado da geração de novos equipamentos e avançadas técnicas de processamento (Hunter et al. 1984, Steeples \& Miller 1990).

Os projetos de sísmica de alta resolução em andamento na UFPR demonstraram até o momento capacidade na caracterização de estruturas rasas em profundidades de até cerca de 300 metros. Entretanto a definição de arranjos de aquisição, assim como o tipo de fonte sísmica consiste em um campo de pesquisa ainda muito amplo e pode ocorrer novas capacidades tanto na resolução quanto na profundidade de investigação.

A figura 3 apresenta um detalhe da área de estudo, mostrando a localização da sísmica regional e de detalhe. Nota-se que a linha de alta resolução posiciona-se sobre a linha regional, permitindo sua correlação espacial.

Linha sísmica regional A Bacia do Paraná dispõe de um grande volume de informações, oriundas de diversos projetos executados pela Petrobrás e pesquisadores das diversas universidades. Especificamente dentro da área de estudo foi realizada uma campanha de aquisi-

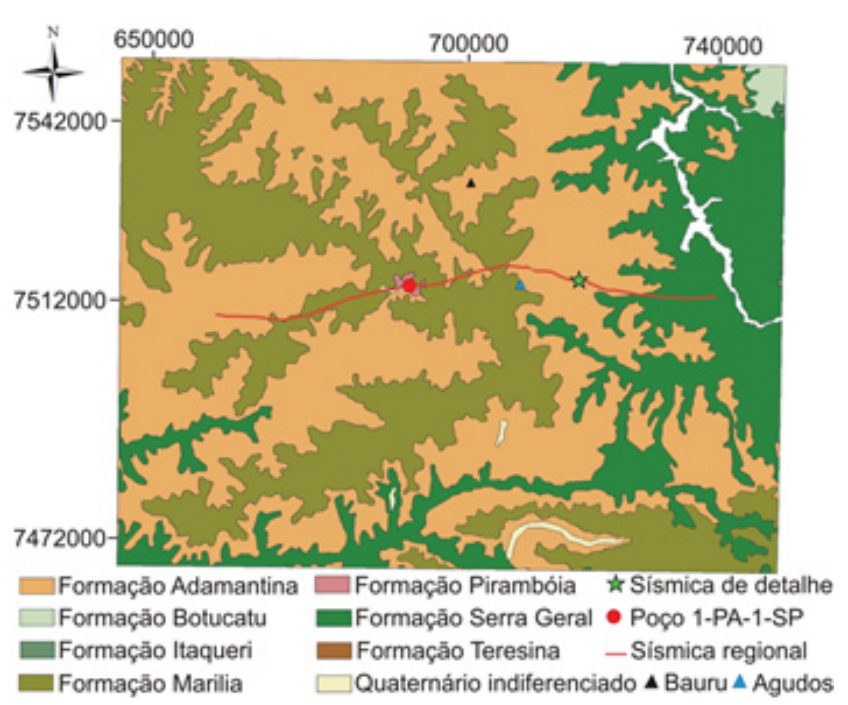

Figura 2 - Mapa geológico regional, com a localização da linha sísmica regional e de detalhe (modificado de IPT 1981).Coordenadas UTM em metros, M.C. $-51^{0}$, SAD 69 .

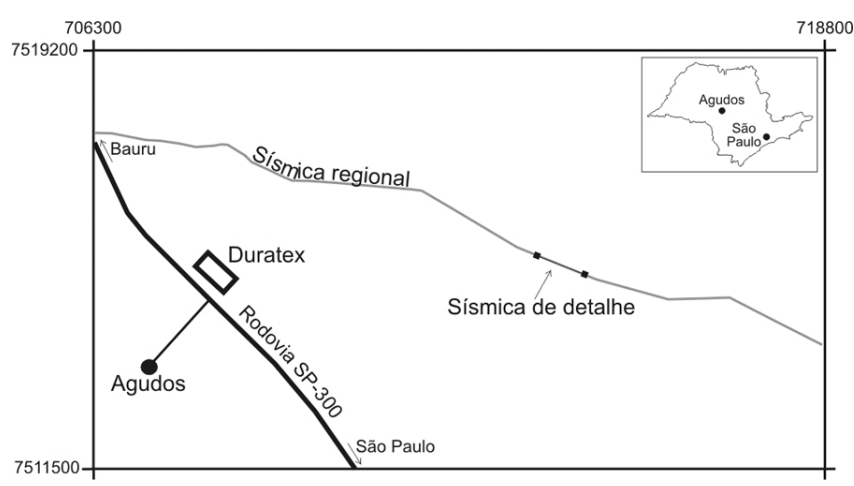

Figura 3 - Detalhe e localização da área de estudo, ressaltando a linha sísmica regional e o posicionamento da linha sísmica de alta resolução. Coordenadas UTM em metros, M.C.-510 , SAD69. 
ção, denominada 0225-0174, tendo como resultado uma seção migrada com cerca de $82 \mathrm{~km}$ de comprimento, localizada próxima ao Domo de Piratininga.

Os dados digitais desta linha sísmica e do poço 1-PA-1-SP foram cedidos pela ANP à Universidade Federal do Paraná. O formato dos dados corresponde a um arquivo em padrão SEG e em formato las, respectivamente. A seção sísmica encontra-se processada de acordo com o banco de dados público disponível na ANP. Aparentemente o processamento foi realizado utilizando um datum flutuante na correção topográfica. Isto significa que o topo do sinal sísmico tem correlação com a variação da elevação ao longo da linha e o tempo da escala vertical encontra-se deslocado do tempo zero em cada posição do terreno.

As seções sísmicas regional e de detalhe foram inseridas no programa computacional Kingdom (licença acadêmica), da empresa Seismic Micro-Technology (SMT), onde passaram por uma etapa de interpretação, com o objetivo de individualizar horizontes e falhas.

Os dados do perfil composto do poço 1-PA-1SP foram úteis na correlação das informações advindas da sísmica e auxiliaram a realização da interpretação das seções sísmicas. O referido poço foi perfurado na década de 80 sobre o Domo de Piratininga, e atingiu 2110 metros de profundidade. Os logs de resistividade e sônico foram utilizados para a correlação com as unidades estratigráficas da Bacia do Paraná. O poço foi inserido dentro do ambiente computacional através da utilização do programa Kingdom. Nesta etapa foram inseridas diversas informações, tais como elevação, coordenadas, profundidade inicial e final. Na seqüên- cia foram inseridos os topos das formações. Na etapa seguinte a curva do sônico foi digitalizada e inserida no banco de dados do projeto. O sônico possui uma superestimação de valores de velocidade em cerca de $15 \%$, que influencia no posicionamento dos topos das formações e compromete a posterior associação com a estratigrafia da bacia. Com base nesta característica foi realizada uma correção das velocidades do sônico antes da conversão profundidade-tempo, sem a qual não é possível visualizar as informações do poço com a seção sísmica no domínio do tempo.

O resultado da interpretação da sísmica regional é apresentado na figura 4. Nesta figura o poço profundo 1-PA-1-SP está localizado no centro da estrutura dômica e apresenta uma zona de baixa refletividade, provavelmente relacionado a um modelo inadequado de velocidades. Esta janela estratigráfica possui características tanto litológicas como sísmicas diferenciadas do entorno exigindo um maior cuidado no empilhamento e análise de velocidade. Entretanto com as informações provindas do $\log$ sônico do poço foi possível interpretar e extrapolar a estratigrafia em toda a seção sísmica, com base da conversão profundidade-tempo.

O Grupo Bauru, aflorante em quase toda a extensão da linha sísmica a exceção da região do Domo de Piratininga, ocorre acima do horizonte H1. Sua espessura é variável e é influenciada pelas condições do relevo. Por sua vez o horizonte H1 é correlacionado ao topo da Formação Serra Geral, e tem como característica sísmica um horizonte marcante e contínuo, embora não apresente continuidade na região do ápice do domo, onde afloram rochas mais antigas (Formação Teresina),

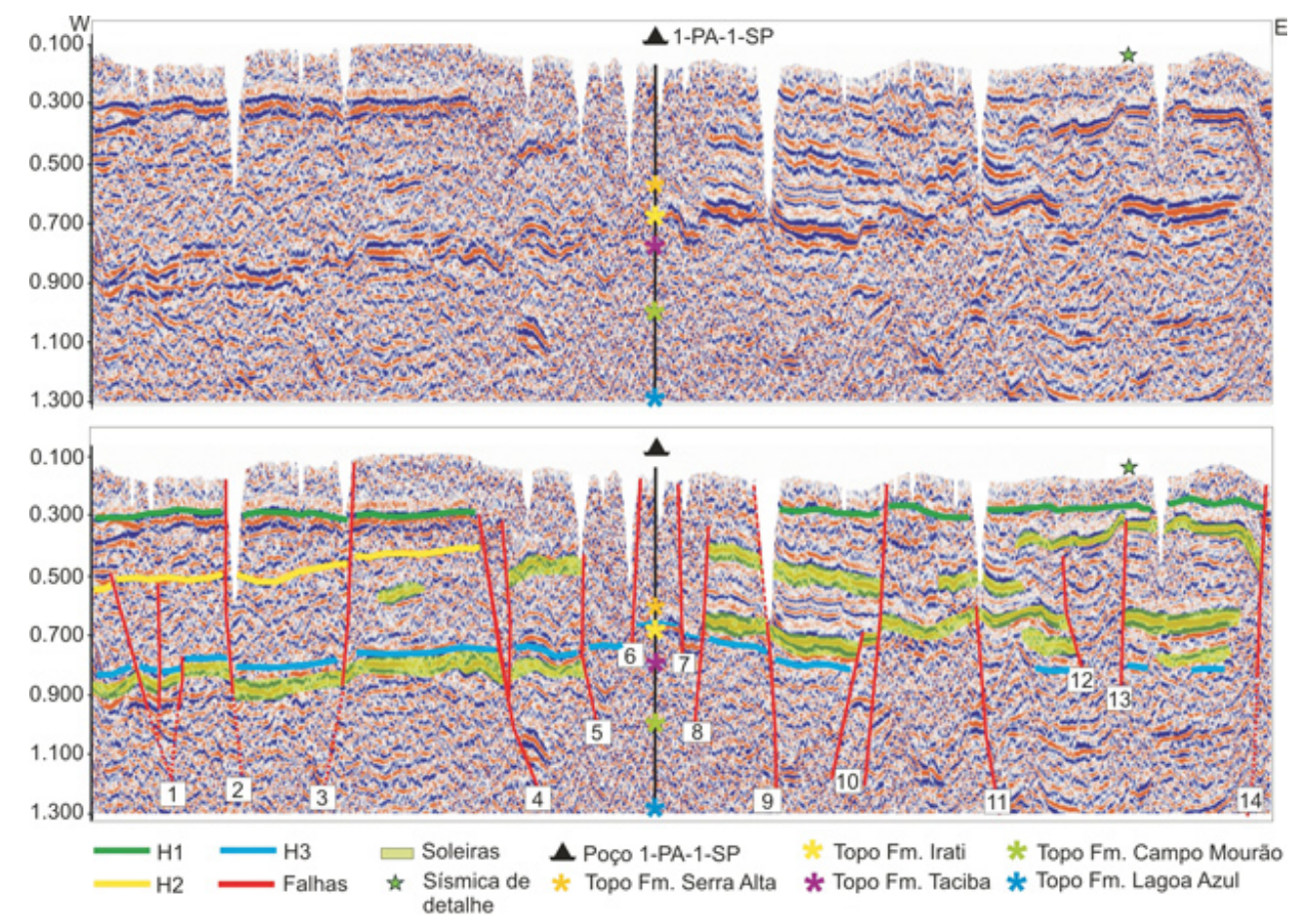

Figura 4 - Seção sísmica regional 225-174 (acima) e interpretação de horizontes, falhas e soleiras (abaixo). 
segundo dados do poço perfurado no local. Entre os horizontes $\mathrm{H} 1$ e $\mathrm{H} 2$ provavelmente ocorrem as rochas correlacionadas as formações Botucatu, Pirambóia/Corumbataí, mas sem apresentar um refletor marcante. O horizonte $\mathrm{H} 2$ pode ser correlacionado a uma interface sísmica presente ao redor do topo da Formação Teresina. Entre os horizontes $\mathrm{H} 3$ e H2 estão contidas as formações Teresina e Serra Alta. O horizonte H3 corresponde ao topo da Formação Irati. Caracteristicamente esta formação apresenta pouca espessura e é relatada a ocorrência de diversas soleiras em seu intervalo, por isso foi considerado que as soleiras identificadas na seção sísmica, principalmente na parte oeste da seção, indicam o posicionamento do topo da Formação Irati. Abaixo do horizonte $\mathrm{H} 3$ ocorrem diversos refletores, mas em função da sua pouca coerência tornou-se difícil sua correlação com os topos das formações Taciba, Campo Mourão e Lagoa Azul, presentes no poço.

Na parte leste da seção existe uma maior quantidade de soleiras, distribuídas em diversos níveis. Existe uma clara diferença na quantidade e distribuição estratigráfica das soleiras entre o leste e o oeste do ápice do domo. As causas prováveis devem estar relacionadas a falhas com caráter extensional de direção NW mais recentes que as falhas de caráter transpressivo de direção $\mathrm{NE}$, que cortam o ápice do domo.

\section{Linha sísmica de detalhe}

AQUISIÇÃO O planejamento original previa a realização dos trabalhos no ápice do Domo de Piratininga, entretanto não foi obtida uma autorização de pesquisa por parte da empresa Louis Dreyfus Commodities Agroindustrial Ltda, proprietária da área que engloba o domo. Em função deste posicionamento da empresa, foi selecionada outra área adjacente para a realização dos estudos.

A escolha do local ficou vinculada à maior proximidade possível com a linha regional e também por apresentar condições apropriadas para a aquisição de dados. A área selecionada está inserida no complexo industrial da empresa Duratex, localizada na Fazenda Monte Alegre, município de Agudos. Através do contato com os responsáveis da Área de Meio Ambiente, Bioecologia \& Relações com a Comunidade, foi obtida a autorização para a realização do levantamento no local, que corresponde a uma estrada interna da fazenda, localizada num setor de reflorestamento de pinus. Uma característica desta estrada é possuir um traçado retilíneo e tráfego quase inexistente de automóveis.

O sistema de aquisição utilizado compreende seis módulos de sismógrafos, de fabricação Geometrics, controlados pelo sistema Seismic Controller através de um laptop Dolch Notepad, especialmente desenhado para condições de campo. Os sismógrafos têm como característica um alcance dinâmico de $144 \mathrm{~dB}$, bandwidth de $1.75 \mathrm{~Hz}$ a $20 \mathrm{kHz}$ e conversão A/D de 24 bits. A fonte sísmica utilizada para a geração de ondas sísmicas foi a queda de peso acelerado, sendo realizados vários tiros numa mesma posição para aumentar a relação sinalruído. Durante a aquisição dos dados foram utilizados geofones de onda $\mathrm{P}$ de $14 \mathrm{~Hz}$ acoplados no solo.

A geometria do arranjo aplicado corresponde ao dispositivo de registro unidirecional (end-on empurrando) com tiros entre os geofones e com utilização de 120 canais ativos durante todo o levantamento. Em cada posição de tiro foram efetuados 3 tiros, cada um registrado num arquivo independente, sem estaqueamento no campo, totalizando cerca de 170 tiros. Os parâmetros de aquisição utilizados nesta linha são apresentados na tabela 1. A profundidade teórica máxima atingida é de cerca de 360 metros.

PROCESSAMENTO O processamento foi realizado com o programa computacional Vista, da empresa Gedco (licença acadêmica), e envolveu inúmeros procedimentos, apresentados na figura 5. As etapas consistem em leitura e importação dos dados, conversão para o formato de processamento utilizado pelo programa, edição com correção da amplitude, análises de velocidades e somatória de traços com a técnica CMP.

INTERPRETAÇÃO A figura 6 apresenta a seção sísmica da linha de alta resolução. Nesta figura é possível observar que ao arranjo sísmico não obteve sucesso no imageamento até $100 \mathrm{~ms}$. No intervalo de 150 a $300 \mathrm{~ms}$ ocorrem refletores contínuos e abaixo de $300 \mathrm{~ms}$ atinge o limite de investigação com o arranjo e fonte utilizados.

$\mathrm{Na}$ seção interpretada foram traçados os horizontes mais marcantes observados no dado. O horizonte $\mathrm{h} 1$ corresponde à parte mais superficial. Apresenta um padrão sísmico de downlap, que pode ser associado com a progradação de clinoformas, formadas durante a

Tabela 1- Parâmetros de aquisição da linha.

\begin{tabular}{l|l}
\hline Intervalo de tiro em metros & 12 \\
\hline Posição do tiro & Entre estações \\
\hline Intervalo de estações em metros & 3 \\
\hline Número de geofones por estação & 1 \\
\hline Número de canais ativos & 120 \\
\hline Near offset em metros & 1.5 \\
\hline Far offset em metros & 358.5 \\
\hline Intervalo de CMP em metros & 1.5 \\
\hline Número de CMP & 552 \\
\hline Comprimento final em metros & 1006.5 \\
\hline Intervalo de amostragem em ms & 0.5 \\
\hline Tempo de registro em segundos & 2 \\
\hline Direção da linha & EW \\
\hline Filtros & Sem filtros \\
\hline Recobrimento & 15 \\
\hline Tamanho em disco em megabytes & 320 \\
\hline Formato de armazenamento & SEG2 \\
\hline
\end{tabular}




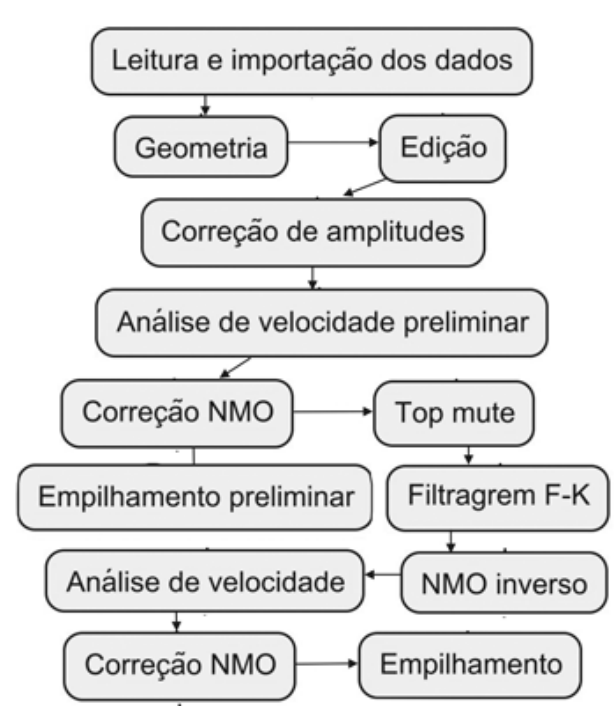

Figura 5 - Fluxograma apresentando a seqüencia de processamento.

deposição. Provavelmente toda esta estratigrafia contida nos domínios do horizonte h1 está correlacionada ao Grupo Bauru. Um outro aspecto deste horizonte é que o mesmo encontra-se com inclinação diferenciada em relação ao horizonte $\mathrm{h} 2$.

$\mathrm{O}$ horizonte $\mathrm{h} 2$ possui eventos mais contínuos que atravessam toda a seção, com uma leve inclinação para oeste, sendo pouco afetado por falhas. Devido ao tempo de ocorrência deste horizonte, por volta de 150$170 \mathrm{~ms}$, correlaciona-se este horizonte com o topo da Formação Serra Geral, identificada na seção regional.

Os horizontes h3, h4 e h5 não tiveram definida uma correlação com a seção regional, principalmente pelo fato de que na sísmica de detalhe existe uma maior resolução no intervalo correspondente a estes horizontes, o que não ocorre na seção regional. Outra característica destes horizontes é que os mesmos são mais afetados por falhas. Provavelmente estas falhas são mais antigas que os horizontes h2 e h1.

Ainda analisando-se a figura 6, nota-se que a partir de $0.370 \mathrm{~ms}$ é marcante a presença de ruídos de aquisição, marcados por refletores inclinados, e que correspondem à ausência de sinal ou ao limite de profundidade de investigação.

AEROMAGNETOMETRIA Os dados utilizados constituem parte dos levantamentos do Projeto Aerogeofísico Bauru e Botucatu executados pela Lasa e Encal, respectivamente, para o consórcio Paulipetro, no período de 1978 a 1980.

Os dados aeromagnéticos do Projeto Bauru foram adquiridos a uma altura média de 450 metros, com intervalo de amostragem de 62 metros, segundo linhas de vôo dispostas na direção NW, espaçadas 2000 metros, e com linhas de controle de direção NE separadas de 20000 metros. Os dados do Projeto Botucatu foram adquiridos a uma altura média de 450 metros, com intervalo de amos-

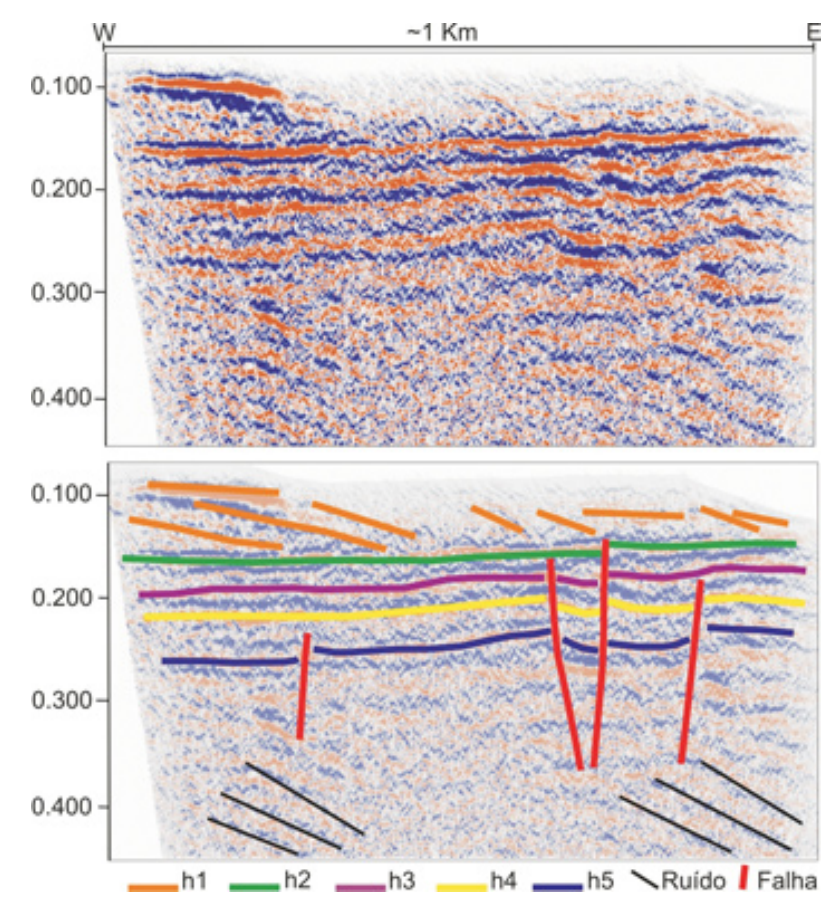

Figura 6 - Seção sísmica da linha de alta resolução (acima) e interpretação de horizontes e falhas (abaixo).

tragem de 100 metros, segundo linhas de vôo dispostas na direção NS, espaçadas 2000 metros, e com linhas de controle de direção EW separadas de 20000 metros.

Os dados digitais de ambos os projetos foram cedidos pelo Laboratório de Estudos de Bacia (LEBAC), do Instituto de Geociências e Ciências Exatas da Universidade Estadual Paulista (UNESP) a Universidade Federal do Paraná.

Processamento O processamento consistiu em uma série de etapas. Na geração do campo magnético anômalo houve a remoção da contribuição referente ao campo magnético principal da Terra (IGRF - International Geomagnetic Reference Field).

$\mathrm{Na}$ seqüência, os dados foram avaliados e interpolados pelo método de curvatura mínima (Briggs 1974), segundo uma malha regular de 500x500 m, correspondentes a $1 / 4$ do espaçamento entre as linhas de vôo. Constatou-se que o mapa assim gerado apresentou artefatos de alta freqüência ao longo das linhas de vôo e que poderiam ser amplificados no processamento. O micronivelamento é utilizado para remover erros residuais de nivelamento de dados aerogeofísicos, por filtragem direcinal. Segundo Geosoft (2001), esta técnica pode ser definida como sendo a filtragem de um conjunto de dados (em forma de grade) para reduzir ou remover efeitos não geológicos causados por ruídos de alto comprimento de onda, ao longo das linhas de levantamento. Para remover e/ou atenuar esses ruídos, foi aplicada a técnica de micronivelamento pelo método de decorrugação FFT (Transformada Rápida de Fourier). Considerando que os projetos Bauru e Botucatu possuem linhas de vôo com direções diferentes, determi- 
nou-se que cada projeto seria micronivelado de forma independente e que somente após este procedimento os dados dos projetos seriam somados e comporiam um único conjunto de dados. $\mathrm{O}$ mapa do campo magnético residual assim gerado é apresentado na figura 7.

A partir do mapa do campo magnético residual micronivelado foram aplicados os filtros de continuação para cima, para simular o campo magnético para alturas superiores aquela do levantamento. Desta forma os dados, adquiridos a uma altura de 450 metros, foram simulados para a altura de 1500 metros. Este procedimento causou a eliminação dos sinais de alta freqüência espacial (ruídos e estruturas menores), preservando as anomalias de grandes comprimentos de onda, reflexo de fontes profundas.

$\mathrm{Na}$ seqüência foi calculada a amplitude do sinal analítico com base na malha do campo magnético continuado para 1500 metros. O método do sinal analítico envolve os gradientes (derivadas) horizontais e vertical de anomalias de campos potenciais. A noção de sinal analítico foi definida inicialmente por Nabighian (1972, 1974), como um "campo complexo derivado de um campo potencial”. Segundo Fuck (2000) o sinal analítico realça estruturas e descontinuidades com expressão magnética, sendo útil no mapeamento de estruturas geológicas. Uma das características do sinal analítico é o fato deste centralizar o sinal sobre a anomalia que o gera. Outro aspecto interessante é que, através de deslocamento de anomalias magnéticas, pode-se estimar a presença de estruturas, como falhas, que por não apresentar uma expressão magnética, não fica evidenciado na forma de anomalias. A figura 8 mostra o mapa da amplitude do sinal analítico, onde se pode observar tendências variadas, com predominância de anomalias na direção NE.

MODELO DIGITAL DE ELEVAÇÃO Os dados do modelo digital de elevação (Fig. 9) foram gerados pelo projeto SRTM, sigla para Shuttle Radar Topography Mission, uma missão em conjunto entre a NASA, NIMA (agência de mapas e imagens norte-americanas), DLR (agência espacial alemã) e ASI (agência espacial italiana). Esses dados foram coletados pelo ônibus espacial Endeavour e proporcionaram a geração de dados altimétricos cobrindo cerca de $80 \%$ da superfície da Terra. Utilizados na forma de modelo digital de elevação (MDE), esses dados altimétricos têm resolução espacial original de $30 \mathrm{~m}$. Os dados disponibilizados pela NASA para a América do Sul foram submetidos à reamostragem espacial para $90 \mathrm{~m}$.

Os dados numéricos utilizados neste trabalho foram obtidos via internet, a partir do sítio da USGS (USGS et al. 2007), em grade formato nativo ARC-Info.

Para o traçado de lineamentos, os dados foram processados basicamente com técnicas de pseudosombreamento e hipsometria. No traçado de lineamentos de relevo adota-se neste trabalho a definição de lineamento indicada por O'Leary et al. (1976), baseada na definição original de Hobbs (1904, apud O'Leary et al. 1976). Estes autores definem os lineamentos como "feições lineares mapeáveis, simples ou compostas, onde as partes estão alinhadas em uma

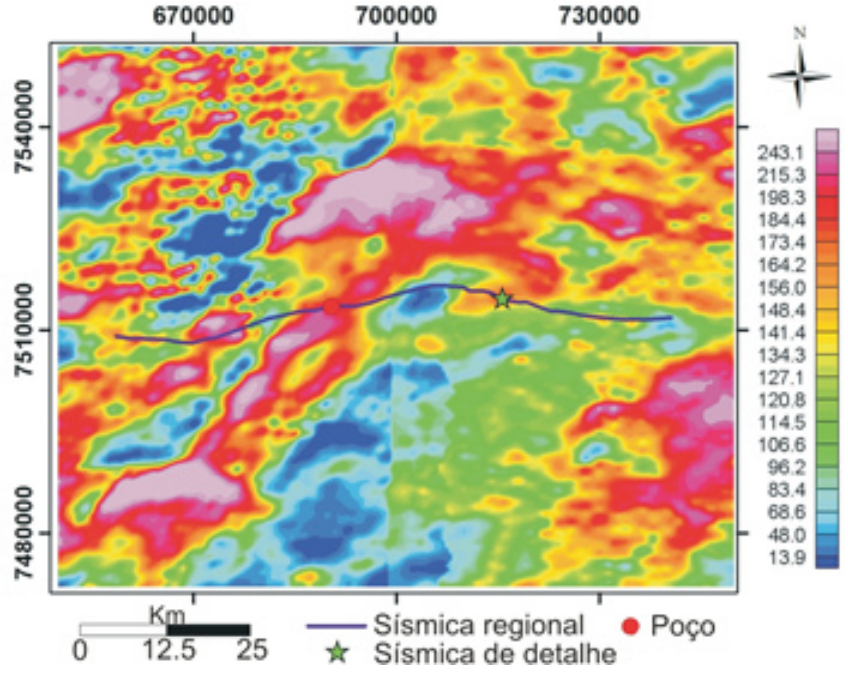

Figura 7 - Mapa do campo total residual micronivelado, com localização do poço 1-PA-1-SP (círculo vermelho), da sísmica regional (linha azul) e da sismica de alta resolução (estrela verde). Coordenadas UTM em metros, M.C.-51 ${ }^{\circ}$ SAD69.

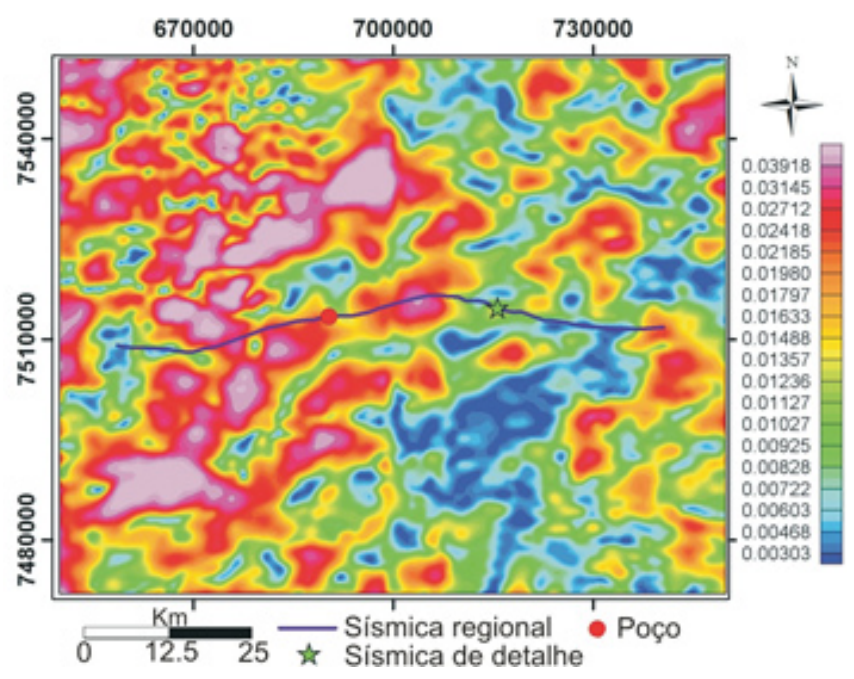

Figura 8 - Mapa da amplitude do sinal analítico, com localização do poço 1-PA-1-SP (círculo vermelho), da sísmica regional (linha azul) e da sísmica de alta resolução (estrela verde). Coordenadas UTM em metros, M.C.-51 ${ }^{\circ}$, SAD69.

relação retilínea ou levemente curva, e que diferem das estruturas adjacentes, provavelmente refletindo um fenômeno de subsuperfície".

A figura 10 apresenta o mapa de lineamentos de relevo, observa-se que os lineamentos de primeira ordem têm direção NE, e são localizados principalmente na parte central da área. Os lineamentos NE têm menor comprimento e são segmentados pelos lineamentos NW.

ARCABOUÇO ESTRUTURAL REGIONAL Para determinar as principais estruturas e sintetizá-las em 


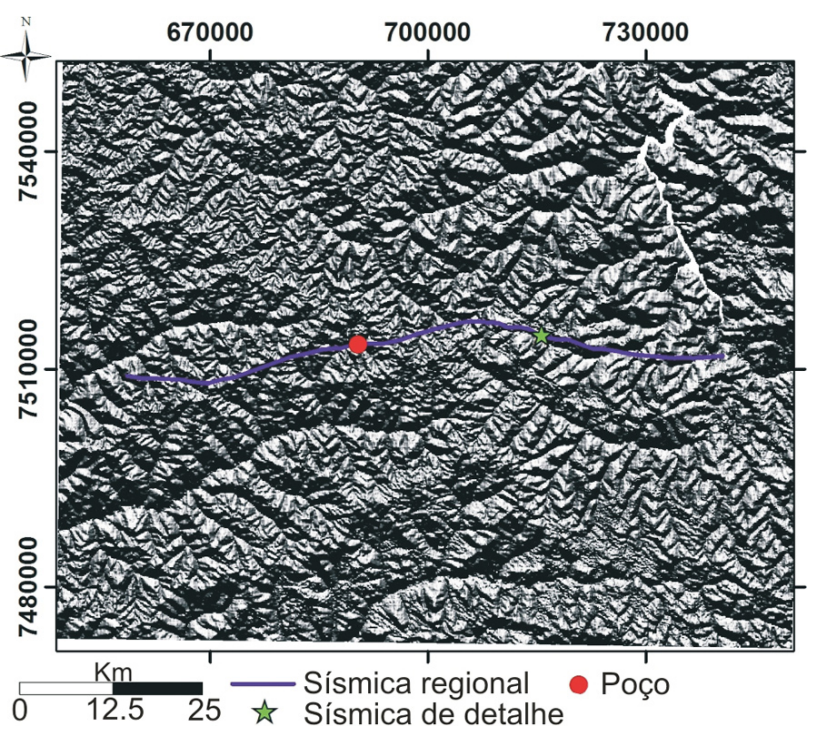

Figura 9 - Modelo digital de elevação com localização da sísmica regional (linha azul), do poço 1-PA-1-SP (círculo vermelho) e da sísmica de alta resolução (estrela verde). Coordenadas UTM em metros, M.C.-51 $1^{0}$, SAD69.

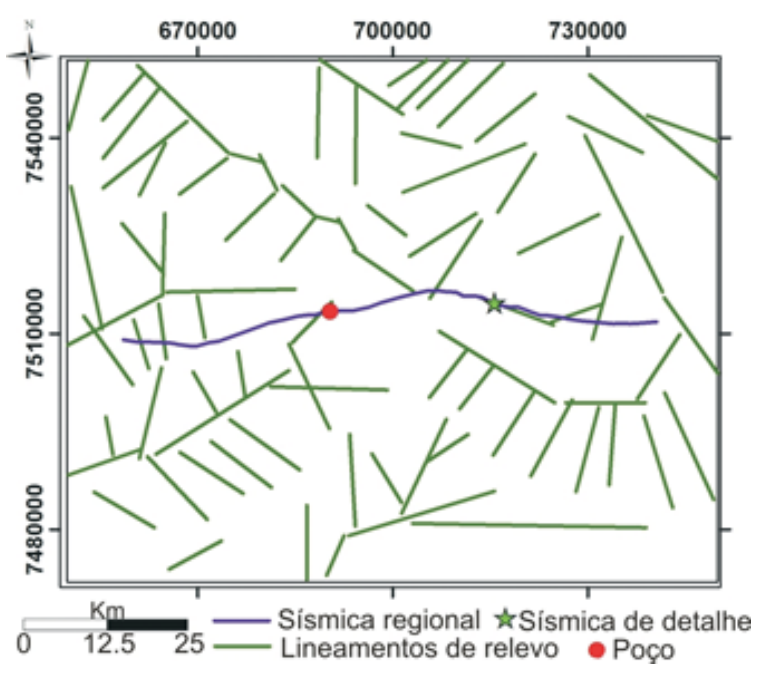

Figura 10 - Mapa de lineamentos do relevo, com localização do poço 1-PA-1-SP (círculo vermelho), da linha sísmica regional (linha azul) e da linha sísmica de alta resolução (estrela verde). Coordenadas UTM em metros, M.C.-510, SAD69.

um arcabouço estrutural, foram interpretados os mapas do sinal analítico, a seção sísmica regional e adicionado os lineamentos revelados pelo MDE.

Com base na figura 8 (mapa do sinal analítico) foram identificados os principais lineamentos magnéticos com expressão regional na área. Os lineamentos positivos são expressos principalmente por cristas (altos alinhados) magnéticas, enquanto que os lineamentos negativos são indicativos de baixos magnéticos. $\mathrm{O}$ traçado e interpretação desses lineamentos resultaram no mapa de lineamentos magnéticos apresentado na figura 11.

$\mathrm{Na}$ análise conjunta dos lineamentos (Fig. 11), foi possível observar que lineamentos de direção NE apresentam assinatura magnética e ocorrem de maneira marcante, distribuídos principalmente na área central de estudo. Estes lineamentos são deslocados e seccionados por grandes lineamentos de direção NW, que não apresentam uma resposta magnética marcante. Provavelmente a gênese dos lineamentos NW e NE possui diferenças em sua idade e conotação tectônica.

Para posicionar a área de estudo dentro de um contexto tectônico mais amplo, foram inseridos num mesmo mapa os lineamentos regionais traçados por Zálan et al. (1990). Na figura 12 é possível observar que a ocorrência de estruturas orientadas na direção NE coincide com a porção norte da Falha de Guaxupé. Secundariamente as estruturas EW podem ser associadas com o Lineamento de Moji-Guaçu - Dourados. Os lineamentos de direção NW são paralelos a Zona de Falha de Guapiara, localizada a sul da área.

A figura 13 apresenta o mapa contendo os lineamentos magnéticos e de relevo, com a indicação das falhas traçadas e/ou interpretadas na seção sísmica regional (indicação do posicionamento em seção das falhas na Fig. 4). Nesta figura é possível observar que um marcante lineamento magnético secciona o Domo de Piratininga, localizado nas imediações do poço 1-PA-1-SP.

$\mathrm{O}$ deslocamento e segmentação de diversos lineamentos NE que possuem uma resposta magnética expressiva, conduziu a interpretação de grandes lineamentos de direção NW, que por sua vez não possuem uma assinatura magnética.

Um aspecto interessante observado na figura 14 é que, de uma forma geral, os lineamentos de relevo negativos (vales alinhados) encontram-se posicionados

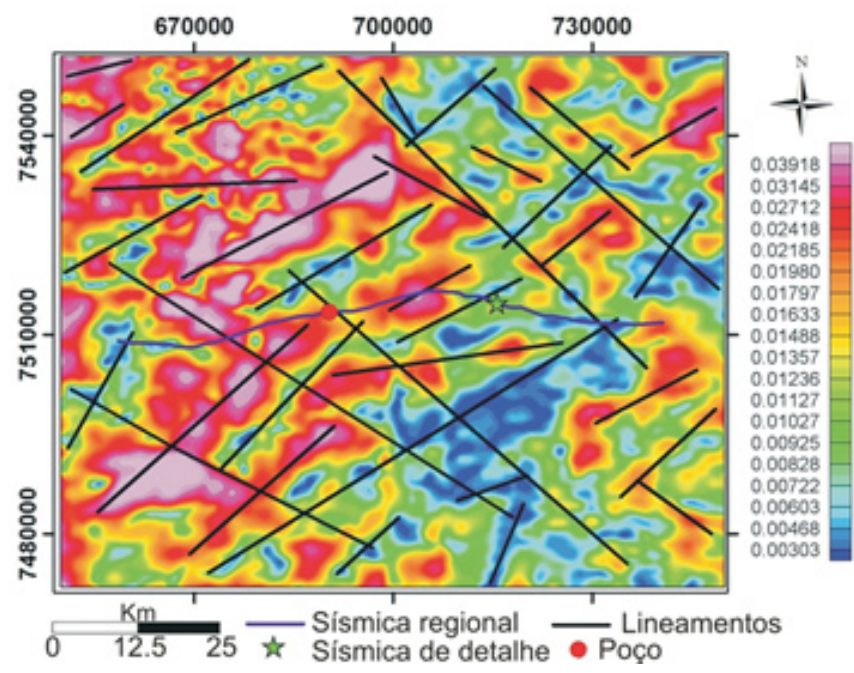

Figura 11 - Mapa dos lineamentos magnéticos, com localização do poço 1-PA-1-SP (círculo vermelho), da linha sísmica regional (linha azul) e da linha sísmica de alta resolução (estrela verde). Coordenadas UTM em metros, M.C.-51 $1^{0}$, SAD69. 


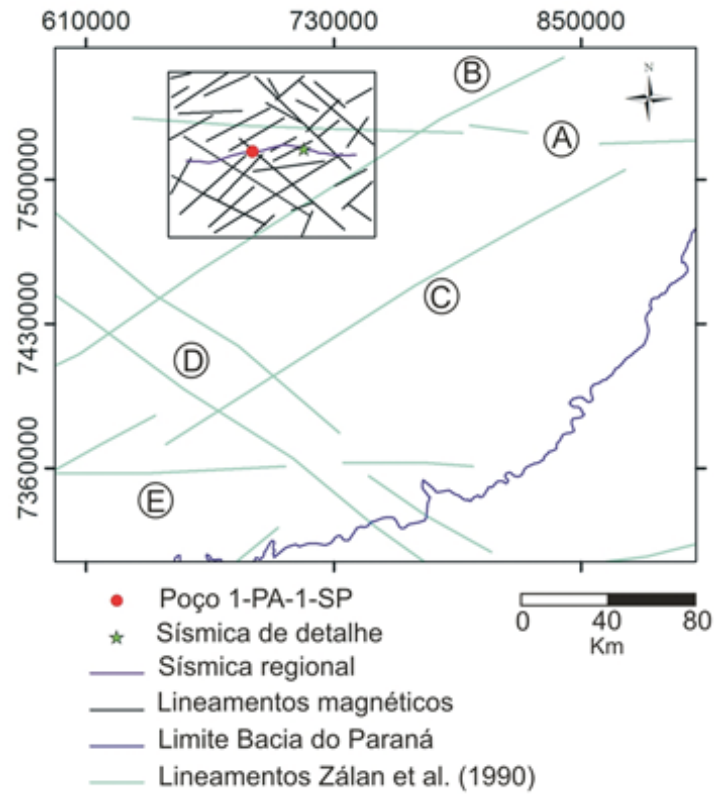

Figura 12 - Posicionamento do mapa do arcabouço magnético-estrutural na Bacia do Paraná, no contexto dos lineamentos estruturais de Zalan et al. 1990. A) Lineamento de Moji-Guaçu-Dourados. B) Falha de Guaxupé. C) Falha de Jacutinga. D) Zona de Falha de Guapiara E) Lineamento de São Sebastião. Coordenadas UTM em metros, M.C.-51 ${ }^{0}$, SAD69.

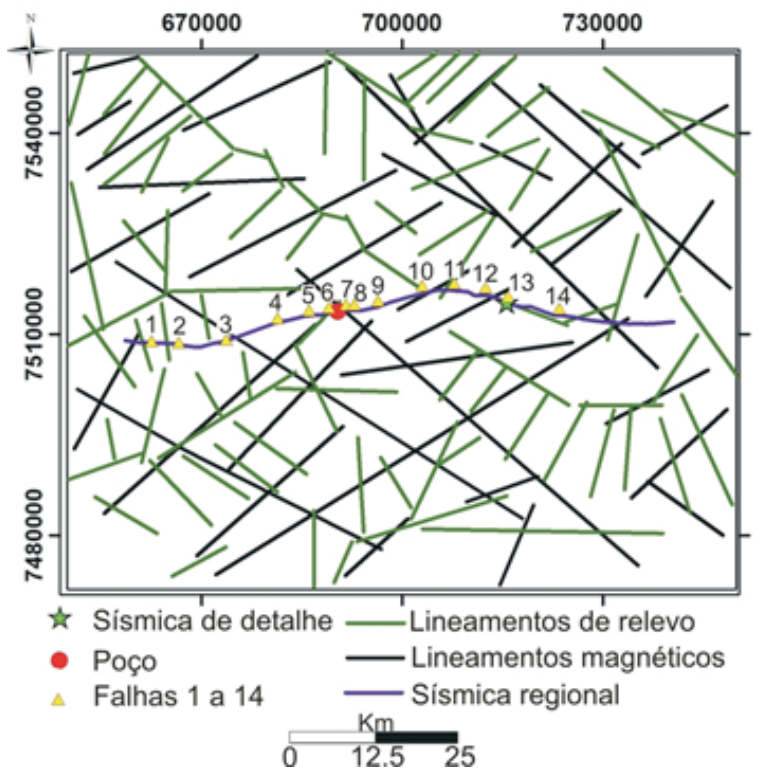

Figura 13 - Lineamentos magnéticos e de relevo, com posicionamento das falhas interpretadas na seção sísmica regional. Coordenadas UTM em metros, M.C.-51 $1^{0}$, SAD69.

sobre anomalias magnéticas positivas. Estas anomalias podem ser associadas a estruturas mais antigas realçadas pelo processamento dos dados magnéticos (conti- nuação para cima).

DISCUSSÕES O conhecimento acerca de características dos reservatórios é impedido ou dificultado porque a resolução nas seções sísmicas regionais não é suficientemente acurada para a realização de trabalhos de detalhe, principalmente quando o enfoque das atividades envolve aspectos como geometrias internas dos reservatórios.

Uma das formas de ampliar este conhecimento envolve a aplicação de procedimentos ou metodologias que permitam a extração de elementos geológicos em diferentes resoluções. Neste sentido a aplicação da sísmica de alta resolução em conjunto com a sísmica tradicional corresponde a uma possibilidade de integrar dados, em diferentes escalas, facilitando e orientando o estudo de análogos de reservatórios.

Embora ocorra uma boa correlação entre os dados magnéticos e do MDE, nem sempre os lineamentos são perfeitamente coincidentes, o que denota diferentes origens para estas feições. Um exemplo desta situação é o lineamento marcante de relevo de direção NW, que ocorre na porção central da área, que nos mapas magnéticos não apresenta uma resposta de mesma magnitude. Embora os resultados apresentem ordens de grandeza distintas, os lineamentos magnéticos e de relevo tem importância, pois possuem relação direta com os aspectos de migração e convergência de fluidos dentro de um reservatório. Segundo Rostirolla et al. (2003) estruturas de maior ordem de grandeza são relacionadas a células de fluxo regionais, sendo as estruturas profundas ou intermediárias responsáveis por grandes volumes de migração. Os mesmos autores apontam como exemplo desta situação as zonas da Falha da Lancinha, Guaxupé e Jacutinga (direção NE) e os lineamentos Rio Piquiri e Cândido de Abreu (direção NW).

As informações integradas a respeito da tectônica parecem sinalizar para a existência de mais de um evento tectônico de grande porte no registro geológico do local de estudo. Rostirolla et al. (2000) desenvolveram uma análise detalhada em área similar (Alto Estrutural de Quatiguá) e observaram um primeiro evento de caráter transcorrente compressional, associado a Orogenia La Ventana, posicionado no final do Permiano. Nesta situação seriam formadas estruturas em flor positivas. $\mathrm{O}$ segundo evento indicado pelos autores, de idade cretácea, apresenta um comportamento transtensional e afetaria as estruturas formadas inicialmente, promovendo um rearranjo de suas características originais.

$\mathrm{Na}$ análise integrada dos produtos deste trabalho notou-se que falhas de direção NE, observadas na seção sísmica e no MDE, ocorrem associadas ao Domo de Piratininga e corresponderiam a um primeiro evento tectônico, de caráter transpressivo. Já as estruturas de direção NW, observadas na seção sísmica regional e nos mapas aeromagnéticos, corresponderiam a outro evento, provavelmente de caráter transtensivo subseqüente.

A figura 15 apresenta um modelo esquemático dos eventos interpretados através da correlação multitemática (sísmica, MDE, aeromagnetometria). As falhas NE podem ter uma ligação com a deformação paleozói- 


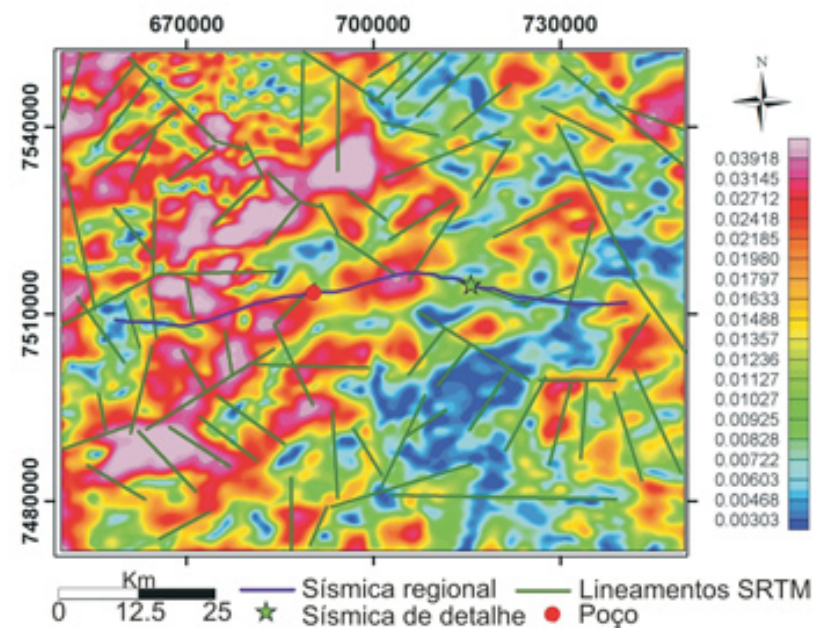

Figura 14 - Mapa da amplitude do sinal analítico, sobreposto aos lineamentos de relevo, com localização do poço 1-PA-1-SP (círculo vermelho), da sísmica regional (linha azul) e da sísmica de alta resolução (estrela verde). Coordenadas UTM em metros, M.C.-510 , SAD69.

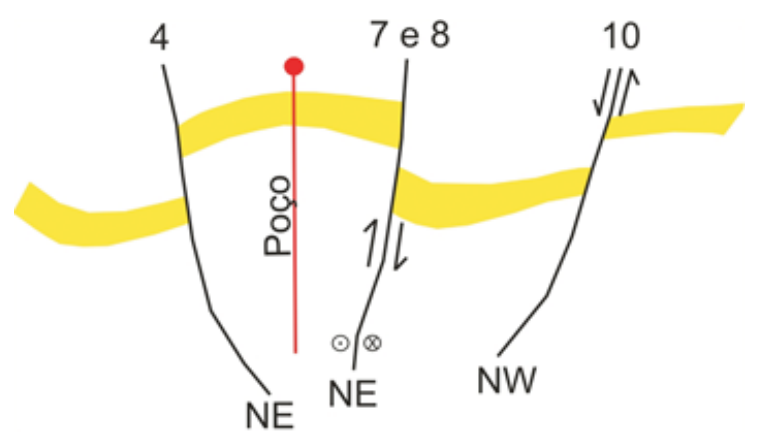

Figura 15 - Modelo esquemático de eventos tectônicos interpretados através da correlação multitemática.

ca, enquanto as falhas de direção NW com a deformação meso-cenozóica. A figura 15 também apresenta as falhas 4,7 e 8 , localizadas na abrangência do ápice do alto estrutural de Piratininga, enquanto a falha 10 , localizada a leste do ápice, representaria o evento tectônico mais recente (Cretáceo ou mais recente).

CONCLUSÕES Na interpretação da seção sísmica regional foi possível reconhecer três horizontes $(\mathrm{H} 1 \mathrm{a}$ H3) correlacionados à estratigrafia da bacia. O horizonte superior (H1) tem uma resposta sísmica marcante e contínua, a exceção da área do ápice do alto estrutural, onde afloram rochas mais antigas (Formação Teresina) do que em seu entorno. O horizonte intermediário $(\mathrm{H} 2)$ possui uma resposta sísmica menos marcante e foi correlacionado com o topo da Formação Teresina. O horizonte basal (H3) foi correlacionado com o topo da Formação Irati, principalmente devido à presença de diversas soleiras. A integração entre as falhas interpretadas na seção sísmica regional e os lineamentos magnéticos e de relevo permitiram identificar dois sistemas principais de falhamentos, um de direção NE e outro NW. Posicionando a área de estudo dentro de um contexto tectônico mais amplo, os lineamentos magnéticos e de relevo foram associados com os lineamentos regionais traçados por Zálan et al. (1990). As estruturas orientadas na direção NE coincidem com a porção norte da Falha de Guaxupé, enquanto que as estruturas de direção NW são paralelas à zona de Falha de Guapiara, localizada a sul da área. A distribuição das soleiras apresenta diferenças entre o leste e o oeste do ápice do alto estrutural, indicando que as falhas com caráter extensional de direção NW são mais recentes que as falhas de caráter transpressivo de direção NE, que cortam o ápice do domo.

Para contemplar a metodologia de multiescala foi adquirida uma linha sísmica de alta resolução paralela a sísmica regional. De maneira geral a seção imageou refletores dentro do intervalo de 0.150 a 0.300 $\mathrm{ms}$. Na interpretação desta seção foram traçados cinco horizontes sísmicos (h1 a h5), sendo o horizonte h1 correlacionado as rochas do Grupo Bauru. O tempo de ocorrência do horizonte h2 tanto na seção de detalhe quanto na regional permitiu a correlação deste horizonte com o topo da Formação Serra Geral. Em função do limite de investigação, relacionado diretamente ao tipo de arranjo e a fonte sísmica, não foi possível correlacionar os horizontes h3, h4 e h5.

A interpretação dos mapas magnéticos permitiu o traçado de dois conjuntos de lineamentos magnéticos. Os lineamentos de direção NE possuem uma assinatura magnética marcante, enquanto que os de direção NW são representados por deslocamentos de anomalias, sem uma resposta magnética forte. $\mathrm{O}$ traçado de lineamentos de relevo no modelo digital de elevação permitiu identificar uma direção principal NW, bem marcante, que secciona os lineamentos de direção NE.

Através da integração dos diversos resultados (sinal analítico interpretado, lineamentos de relevo, interpretação de horizontes e falhas na seção sísmica regional) foi possível estabelecer pelo menos dois eventos tectônicos distintos na área de estudo. Para a área estudada os lineamentos NW e secundariamente NE parecem exercer influência significativa na compartimentação do arcabouço estrutural. Este aspecto fica claro quando observamos a seção sísmica interpretada e o mapa do sinal analítico.

Esta metodologia de correlação de informações ora visualizadas no detalhe (sísmica de alta resolução) ora no regional (sísmica regional) configura e demonstra o potencial de aplicabilidade da análise multiescala, como forma de facilitar e orientar o estudo de análogos de reservatórios.

Agradecimentos Os autores agradecem a empresa Duratex pelo apoio completo a pesquisa, assim como aos integrantes do Laboratório de Análise de Bacias e Petrofísica (LABAP), da Universidade Federal do Paraná pela ajuda 
nos trabalhos de campo. A FINEP e a Petróleo Brasileiro (Petrobrás) pelo apoio financeiro. A Gedco e a Seismic
Micro-Technology pela cessão da licença acadêmica dos programas Vista e Kingdom, respectivamente.

\section{Referências}

Artur P.C. 1998. Paleolineamentos na Bacia do Paraná: Favorabilidade para acumulação de petróleo. Dissertação de Mestrado, Universidade Federal do Paraná, 202 p.

Briggs 1974. Machine contouring using minimum curvature. Geophysics, 39:39-48.

De Freitas R.F. 2005. Análise estrutural multitemática do Sistema Petrolifero Irati-Rio Bonito, Bacia do Paraná. Dissertação de Mestrado, Universidade Federal do Paraná, 116 p.

Ferreira F.J.F. 1982. Integração de dados aeromagnéticos e geológicos: Configuração e evolução tectônica do Arco de Ponta Grossa. Dissertação de Mestrado, Instituto de Geociências, Universidade de São Paulo, 170 p.

Fernandes L.A. 1998. Estratigrafia e evolução geológica da parte oriental da Bacia Bauru (Ks, Brasil). Tese de Doutoramento, Instituto de Geociências, Universidade de São Paulo, 216 p.

Fernandes L.A. \& Coimbra A.M. 2000. Revisão estratigráfica da parte oriental da Bacia Bauru (Neocretáceo). Revista Brasileira de Geociências, 30:717-728.

Fuck R.F. 2000. Interpretação de dados magnetométricos, eletromagnetométricos e gamaespectométricos da região central da Serra do Carajás, PA. Dissertação de Mestrado, Instituto de Geociências, Universidade de Brasília, 185 p.

GEDCO. Vista Seismic Data Processing, version 6.0. Calgary, Alberta, Canadá. Programa 1 CD-ROM.

Geosoft 2001. Microlevelling using bi-directional gridding. Geosoft Technical Note, Geosoft Inc, 4 p.

Hunter J.A, Pullan S.E., Burns R.A., Gagne R.M., Good R.S. 1984. Shallow seismic reflection mapping of the overburden-bedrock interface with the engineering seismograph some simple techniques. Geophysics, 60:1051-1057.

INSTITUTO DE PESQUISAS TECNOLÓGICAS DO ESTADO DE SÃO PAULO (IPT). 1981. Mapa Geológico do Estado de São Paulo. Escala 1:500.000, Volume I, São Paulo: IPT, $126 \mathrm{p}$.

Nabighian M.N. 1972. The analytical signal of two-dimensional magnetic bodies with polygonal cross-section: its properties and use for automated anomaly interpretation. Geophysics, 37:507-517.

Nabighian M.N. 1974. Additional comments on the analytical signal of two-dimensional magnetic bodies with polygonal cross-section. Geophysics, 39:85-92.

O'Leary D.W., Friedman J.D., Pohn, H.A. 1976. Lineament, linear, lineation: some proposed new standarts for old terms. Geological Society America Bulletin, 87:1463-1469.

PAULIPETRO 1981. Relatório de Atividades 1979/1981, 59 p.

Riccomini C. 1997. Arcabouço estrutural e aspectos do tectonismo gerador e deformador da Bacia Bauru no estado de São Paulo. Revista Brasileira de Geociências, 27(2):153-162.

Rostirolla S.P., Assine M.L., Fernandes L.A., Artur P.C. 2000.
Reativação de paleolineamentos durante a evolução da Bacia do Paraná - O exemplo do alto estrutural de Quatiguá. Revista Brasileira de Geociências, 30(4):639-648.

Rostirolla S.P., Appi C.J., Vesely F.F., Trzaskis-Lipski B., Mancini F., Kraft R. 2003. Análise preliminary de rotas de migração de gás no Sistema Petrolífero Ponta GrossaItararé(!), Bacia do Paraná. In: Simpósio Nacional de Estudos Tectônicos, 9, Búzios, Boletim de Resumos, p. 358-360.

SEISMIC MICRO-TECHNOLOGY. Kingdom Suite, version 8.1. Texas, USA. Conjunto de programas $1 \mathrm{CD}-\mathrm{ROM}$.

Soares P.C., Barcellos P.E., Csordas S.M. 1982. Análise, interpretação e integração de lineamentos a partir de imagens (Radar-Landsat) e suas relações com a tectônica da Bacia do Paraná. São Paulo, Paulipetro, Consórcio CESP/IPT.

Soares P.C. 1991. Tectônica sin-sedimentar cíclica na Bacia do Paraná: controles. Tese de Titular, Universidade Federal do Paraná, 148 p.

Soares P.C., Landim P.M.B., Fúlfaro V.J., Sobreiro Neto A. F. 1980. Ensaio de caracterização estratigráfica do Cretáceo no estado de São Paulo: Grupo Bauru. Revista Brasileira de Geociências, 10:177-185.

Steeples D.W. \& Miller R.D. 1990. Seismic reflection methods applied to engineering, environmental and groundwater problems. In: Ward S. (ed.) Geothecnical and environmental geophysics. Vol. 1: Review and Tutorial. Tulsa, SEG publications, p.1-30.

Suguio K. 1981. Fatores paleoambientais e paleoclimáticos e subdivisão estratigráfica do Grupo Bauru. In: SBG, Mesa redonda sobre a Formação Bauru no Estado de São Paulo e adjacências, 1, São Paulo, Coletânea de Trabalhos e Debates, Publicação Especial, 7:15-26.

USGS - Eros Data Center - Data Services Branch. Seamless Data Distribution System. Disponível em: http://seamless. usgs.gov/. Acesso em 18/08/2007.

Zalán P.V., Wolff S., Astolfi M.A.M., Vieira I.S., Conceição J.C.J., Appi V.T., Neto E.V.S, Cerqueira J.R., Marques A. 1990. The Paraná Basin, Brazil. In: Leighton M.W., Kolata D.R., Oltz D.F., Eidel J.J. (eds.) Interior Cratonic Basins. AAPG Memoir 51:681-708.

Zalán P.V., Wolff S., Astolfi M.A.M., Vieira I.S., Appi V.T., Zanotto O.A. 1987. Tectônica e sedimentação da Bacia do Paraná. In: SBG, Simpósio Sul-Brasileiro de Geologia, 1, Atas, p. 441-473.

Manuscrito BR 17

Submetido em 21 de dezembro de 2007 Aceito em 17 de abril de 2008 